Inequality, Debt Servicing and the Sustainability of Steady State Growth

Mark Setterfield, Yun K. Kim and Jeremy Rees

WORKING PAPER 2014-11

DEPARTMENT OF ECONOMICS

UNIVERSITY OF MASSACHUSETTS BOSTON 


\title{
Inequality, Debt Servicing, and the Sustainability of Steady State Growth*
}

\author{
Mark Setterfield $\dagger^{\dagger}$ Yun K. Kim ${ }^{\ddagger}$ and Jeremy Rees ${ }^{\S}$
}

October 24, 2014

\begin{abstract}
We investigate the claim that the way in which debtor households service their debts matters for macroeconomic performance. A standard Kaleckian growth model is modified to incorporate working households who borrow to finance consumption that is determined, in part, by the desire to emulate the consumption patterns of more affluent households. The impact of this behavior on the sustainability of the growth process is then studied by means of a numerical analysis that captures various dimensions of income inequality. When compared to previous contributions to the literature, our results show that the way in which debtor households service their debt has both quantitative and qualitative effects on the economy's macrodynamics.
\end{abstract}

Key words: Consumer debt, emulation, income distribution, Golden Age regime, Neoliberal regime, expenditure cascades, growth

JEL classifications: E12, E44, O41

\section{Introduction}

A substantial literature connects the relatively rapid growth of the US economy during the Great Moderation to aggressive increases in household indebtedness that offset the otherwise negative impact on consumption spending of increased income inequality (Palley, 2002;

*Earlier versions of this paper were presented at the meetings of the Eastern Economic Association, Boston, March 2014, the Review of Political Economy Malvern Conference, Great Malvern, July 2014, and the VII Encontro Internacional da Associação Keynesiana Brasileira (AKB), São Paulo, August 2014. The authors would like to thank conference participants for their helpful comments. Any remaining errors are our own. Mark Setterfield would like to thank the Institute for New Economic Thinking and the Dana Foundation for generous financial support that facilitated his work on this paper.

†Department of Economics, New School For Social Research, New York, NY 10003 and Trinity College, Hartford; mark.setterfield@newschool.edu.

${ }_{\ddagger}^{\ddagger}$ University of Massachusetts, Boston; yun.kim@umb.edu.

$\S$ Trinity College, Hartford. 
Cynamon and Fazzari, 2008; Barba and Pivetti, 2009; Wisman, 2013; Setterfield, 2013). According to Setterfield and Kim (2013), in the presence of emulation effects in consumption behavior and fundamental uncertainty about the long-term consequences of debt accumulation, rising income inequality of the sort witnessed in the US since 1980 can boost growth but simultaneously undermine the sustainability of the growth process. The authors also show that not only increased borrowing per se but also the increased debt servicing that inevitably accompanies debt accumulation tend to raise the rate of growth. This last result runs counter to conventional Keynesian logic, according to which debt servicing redistributes income toward low spending (at the margin), affluent households and therefore exerts a drag on demand formation. The results of Setterfield and Kim (2013) are, however, based on a particular characterization of household debt servicing behavior, according to which households treat debt servicing as a cash outlay or expense rather than as a deduction from income (Cynamon and Fazzari, 2014). In so doing, they first consume from their income, then service their debts, and then save what remains as a residual. The purpose of this paper is to investigate whether or not the results of Setterfield and Kim (2013) survive if households service their debts "conventionally", by treating debt servicing as a deduction from income and then consuming some fraction of what remains. This enables us to explore further a key hypothesis of Setterfield and Kim (2013), that not only debt servicing per se but the precise manner in which debtor households service their debts affects macroeconomic performance.

The remainder of the paper is organized as follows. In section 2, we describe features of our basic model, including its stock-flow consistency. Key attributes of firm and, in particular, household behavior are outlined, and short-run equilibrium outcomes and the comparative statics associated with these outcomes are derived. Section 3 then explores the impact of debt servicing behavior on the sustainability of the growth process by means of a numerical analysis. The fourth section offers some conclusions, chief among which is that the way in which debtor households service their debts has both qualitative and quantitative effects on the economy's macrodynamics. 


\section{Model Structure}

\subsection{Stock-Flow Consistency}

Following Setterfield and Kim (2013), our model consists of banks, firms, and two types of households - working households who borrow to finance some part of their current consumption and rentier households who do not. The balance sheet and transaction flow relationships between these agents are described in the social accounting matrices (SAMs) in Tables 1 and 2. Note that because our focus is on household behavior, both firms and banks are highly simplified. Firms produce, set prices, and invest, their investment expenditure funded entirely by capitalists who purchase equities. ${ }^{1}$ Banks, meanwhile, act as passive intermediaries between households. They earn no income from the intermediation services they provide and accumulate no net worth.

Table 1: Balance Sheet Matrix

\begin{tabular}{lccccc}
\hline & Workers & Rentiers & Firms & Banks & Sum \\
\hline Capital & & & $K$ & & $K$ \\
Deposits & $D_{W}$ & $D_{R}$ & & $-\left(D_{W}+D_{R}\right)$ & 0 \\
Loans & $-D$ & & & $D$ & 0 \\
Equity & & $E$ & $-E$ & & 0 \\
Net worth & $D_{W}-D$ & $D_{R}+E$ & $K-E$ & $D-\left(D_{W}+D_{R}\right)$ & $K$ \\
\hline
\end{tabular}

Total income in the economy can be described as:

$$
Y=W_{p} N+W_{r} \alpha N+\Pi
$$

where $Y$ denotes real income, $\Pi$ denotes total real profits, $W_{p}$ is the real wage of production workers, $W_{r}$ is the real wage of supervisory workers, $N$ is the number of production workers employed, and $\alpha<1$ denotes the necessary ratio of managers to production workers (given by technology and the organizational structure of the production process). In equation (1), $W_{p} N$ is the income of working (net debtor) households and $W_{r} \alpha N+\Pi$ is the income of

\footnotetext{
${ }^{1}$ For simplicity, the price of equity is fixed and normalized to one.
} 
Table 2: Transaction Flow Matrix

\begin{tabular}{|c|c|c|c|c|c|c|c|}
\hline & \multirow[b]{2}{*}{ Workers } & \multirow[b]{2}{*}{ Rentiers } & \multicolumn{2}{|c|}{ Firms } & \multicolumn{2}{|c|}{ Banks } & \multirow[b]{2}{*}{ Sum } \\
\hline & & & Current & Capital & Current & Capital & \\
\hline Consumption by wage & $-C_{W}$ & $-C_{R}$ & $C_{W}+C_{R}$ & & & & 0 \\
\hline Consumption by debt & $-\dot{D}$ & & $\dot{D}$ & & & & 0 \\
\hline Investment & & & $I$ & $-I$ & & & 0 \\
\hline Wages & $W_{p} N$ & $W_{r} \alpha N$ & $-W$ & & & & 0 \\
\hline Firms' profits & & $\Pi$ & $-\Pi$ & & & & 0 \\
\hline Deposit interest & $i D_{W}$ & $i D_{R}$ & & & $-i\left(D_{W}+D_{R}\right)$ & & 0 \\
\hline Loan interest & $-i D$ & & & & $i D$ & & 0 \\
\hline Deposit flows & $-\dot{D_{W}}$ & $-\dot{D_{R}}$ & & & & $\left(\dot{D_{W}}+\dot{D_{R}}\right)$ & 0 \\
\hline Loan flows & $\dot{D}$ & & & & & $-\dot{D}$ & 0 \\
\hline Issues of equities & & $-\dot{E}$ & & $\dot{E}$ & & & 0 \\
\hline Sum & 0 & 0 & 0 & 0 & 0 & 0 & 0 \\
\hline
\end{tabular}

rentier (net creditor) households, the latter made up of capitalists and supervisory workers. Following Palley (2013b), this distinction follows from the observation that there are marked differences, in terms of income and wealth shares, between the bottom 80 per cent and the top 20 per cent of the US income distribution, with the bottom 80 per cent corresponding to the working class, ${ }^{2}$ and the top 20 per cent corresponding to the middle class (including the upper middle class of capitalists and the "working rich" who make up the top one per cent of the income distribution). ${ }^{3}$

Note from Tables 1 and 2 that rentier households fund only part of the debt accumulated by working households: the remainder is funded by other working households, as a result of the assumption that workers save even as they borrow. ${ }^{4}$ This assumption can be justified as follows. First, working households are heterogeneous: some fully fund consumption

\footnotetext{
${ }^{2}$ Production and non-supervisory workers account for 80 per cent of all employees in the US economy.

${ }^{3}$ The "working rich" refers to upper-level salaried employees who have, in increasing numbers, joined capitalist households at the very top of the income distribution over the last thirty years. See Piketty and Saez (2003), Wolff and Zacharias (2009) and Atkinson et al. (2011) on the evolution of "top incomes" in the US. See also Mohun (2006) on the correct accounting treatment of the "wage" income earned by the "working rich", and Wolff and Zacharias (2013) on the relationship between social class and the size distribution of income.

${ }^{4}$ Notice that, following Skott $(1989,2014)$, working households accumulate wealth only in the form of interest-earning bank deposits: all corporate equity is owned by rentiers. This differs from the approach taken by Pasinetti (1962) and Palley (2012), in which physical capital is the only asset that households can own, so that workers who save own equity (and therefore receive some share of profit income). Clearly, the two approaches are not mutually exclusive, and the consequences of equity ownership by working households are worthy of further investigation in future research.
} 
from current income and save, while others save nothing and simultaneously consume more than they earn by borrowing. Second, in an environment of fundamental uncertainty and imperfect credit markets, it is rational for any individual household that wishes to consume in excess of current income to simultaneously save and borrow (Setterfield and Kim, 2013). This is because uncertainty implies a precautionary demand for liquidity to meet unforeseen contingencies, while imperfect credit markets mean that dis-saving and borrowing are not perfect substitutes: a household is always legally entitled to draw down previously accumulated wealth, but has no right to borrow.

\subsection{Production, Pricing and Investment}

As noted above, banks are passive intermediaries and their behavior requires no further exploration. Firms, however, engage in production, pricing and investment behavior that contributes to the structure of our model and demands investigation.

Production results from a fixed coefficient production function of the following form:

$$
Y=\min \{\kappa K, \varepsilon M i n[N, M / \alpha]\}
$$

where $M$ denotes the number of managers. ${ }^{5}$ The fixed real wage earned by workers is assumed to be a fraction of the real wage of managers, or:

$$
W_{r}=\phi W_{p}
$$

where $\phi>1$. Total real wage income is then:

$$
\begin{array}{r}
W=W_{p} N+W_{r} M \\
\Rightarrow W=W_{p} N+\phi W_{p} \alpha N=(1+\phi \alpha) W_{p} N
\end{array}
$$

\footnotetext{
${ }^{5}$ See also Palley (2013a).
} 
Denoting workers' wage share of total income as $\omega_{p}$ and managers' wage share as $\omega_{r}$, it follows that:

$$
\omega_{r}=\phi \alpha \omega_{p}
$$

Note, then, that on the basis of equations (1) and (5):

$$
\begin{array}{r}
1-\pi=(1+\phi \alpha) \omega_{p} \\
\Rightarrow \omega_{p}=\frac{1-\pi}{1+\phi \alpha}
\end{array}
$$

Firms set prices in standard neo-Kaleckian fashion, by marking up unit labor costs, (Harris, 1974; Asimakopulos, 1975). The gross profit share $(\pi=\Pi / Y)$ is then:

$$
\pi=\frac{\tau}{1+\tau}
$$

where $\tau$ is the (fixed) mark up applied to unit labor costs to determine prices.

Finally, following Stockhammer (1999), firms' desired investment rate $\left(g_{K}=I / K\right)$ is described as:

$$
g_{K}=\kappa_{0}+\kappa_{r} r
$$

where $r=\Pi / K$ is the rate of profit. The parameters in this investment function are positive: $\kappa_{0}$ captures the state of business confidence or "animal spirits"; and $\kappa_{r}$ captures the sensitivity of desired investment to the profit rate. The current profit rate approximates the expected rate of return, and hence changes in $r$ induce variations in planned investment spending (Blecker, 2002; Stockhammer, 1999). Since the profit rate is just the product of the profit share and the capacity utilization rate $(u=Y / K)$, the rate of accumulation in equation (8) can be expressed as:

$$
g_{K}=\kappa_{0}+\kappa_{r} \pi u
$$




\subsection{Consumption Behavior}

From Table 2, aggregate consumption $(C)$ can be written as:

$$
C=C_{W}+C_{R}+\dot{D}
$$

Note that borrowing by working households, $\dot{D}$, results in the accumulation of debt by these households and hence the accumulation of an equivalent stock of financial wealth by other households. The influence of debt on consumption is discussed in detail below. We abstract from the influence of financial assets (and wealth in general) on consumption spending, however, for the sake of simplicity. Stylized facts (an extremely unequal distribution of wealth - and particularly financial assets - coupled with small marginal propensities to spend on the part of the most affluent members of society) suggest that the marginal impact of wealth on aggregate consumption is modest. ${ }^{6}$

The individual components of equation (10) are modeled as follows. First, we describe consumption by rentiers as a fixed proportion of their total wage, profit, and interest income:

$$
\left.C_{R}=c_{\pi}\left[W_{r} \alpha N+\Pi+i D_{R}\right)\right]
$$

Consumption spending by workers, meanwhile, is made up of two components. First, consumption financed by borrowing is characterized as:

$$
\dot{D}=\beta\left(C^{T}-C_{W}\right), \beta>0
$$

where $C^{T}$ denotes a target level of consumption to which working households aspire, specified as:

$$
C^{T}=\eta C_{R}
$$

The adjustment parameter $\beta$ in equation (12) depends on household borrowing norms and

\footnotetext{
${ }^{6}$ For empirical evidence supporting these claims, see Wolff (2010) and Onaran et al. (2011).
} 
financial market lending norms, and is taken as given. Note that borrowing only partially closes the gap between $C^{T}$ and $C_{W}$ at any point in time. In other words, working households generally consume at levels below those to which they aspire. In equation (13), workers attempt to emulate rentier consumption. ${ }^{7}$ The influence of rentier consumption on that of working households may be direct, working through representations of rentier lifestyles in the mass media (Cynamon and Fazzari, 2008; Bartolini et al., 2014). ${ }^{8}$ Alternatively it may be an indirect consequence of the "expenditure cascades" outlined by Frank et al. (2014), according to whom the consumption patterns of the most affluent households influence the consumption patterns of their (geographically and economically) near neighbors, who influence the consumption patterns of their near neighbors, and so on. The larger the emulation parameter $\eta$, the higher the target level of consumption $C^{T}$ in equation (13) and the more debt financed consumption is undertaken by workers in equation (12).

The second component of workers' consumption is consumption spending funded by current income. In Setterfield and Kim (2013):

$$
C_{W}=c_{W} W_{p} N
$$

${ }^{7}$ Equation (13) can be thought of as a simplification of the more general expression:

$$
C^{T}=\eta_{n} C_{n}+\eta_{R} C_{R}+\eta_{E} E\left(W_{p} N \mid \Omega\right)
$$

where $C_{n}$ denotes a "normal" level of consumption established in the past and $\Omega$ is the incomplete information set that provides the basis for expectations formation in an environment of uncertainty. This expression is consistent with the claim of Kahneman et al. (1986), that aspirations (such as $C^{T}$ ) are based largely on objective observations of past outcomes and outcomes experienced by others. Note that increases in $C^{T}$ may involve distinctly defensive or restorative behaviors by households. For example, as an expression of private consumption norms, $C_{n}$ may increase because the erosion of public services such as health care requires private provision of these services if household welfare is to remain unchanged, or because acquisition of market goods (such as alarm systems) is required to redress the erosion of social capital (such as trust)(Bartolini et al., 2014). Increases in $C^{T}$ and the household borrowing and indebtedness to which they give rise may, therefore, reflect efforts by households to merely maintain (rather than increase) overall consumption and/or welfare. The simplification in equation (13), however, focuses attention exclusively on outcomes experienced by others as a "driver" of $C^{T}$, and hence on the process of emulation in consumption behavior that is central to this paper.

${ }^{8}$ Bartolini et al. (2014, pp.1030-1031) argue that "powerful industries (advertising, media culture, etc.) present in contemporary market economies have successfully pushed people into substituting short-term materialistic wants, which can be satisfied on the marketplace, for long-term happiness, which can be pursued by investing time and effort to develop deep interpersonal relations." This suggests that the locus of responsibility for the propensity to emulate (and any increases therein) is contestable: it may reside with the individual or society (or both). 
and:

$$
S_{W}=\left(1-c_{W}\right) W_{p} N-i D_{R}
$$

In other words, workers' behavior conforms to a distinct hierarchy or "pecking order", according to which they first consume from current income, then service their debts, and finally treat saving as a residual determined by prior consumption and debt servicing outlays. In this paper, we write:

$$
C_{W}=c_{W}\left(W_{p} N-i D_{R}\right)
$$

so that:

$$
S_{W}=\left(1-c_{W}\right)\left(W_{p} N-i D_{R}\right)
$$

This involves a more conventional treatment of debt servicing as an initial deduction from income, the remainder of which is then either consumed or saved. The key question addressed in what follows is whether, and if so how, this affects the macrodynamics of the economy.

\subsection{Temporary Equilibrium and Comparative Statics}

Commodity market equilibrium can be stated as:

$$
Y=C_{W}+C_{R}+\dot{D}+I
$$

By substituting equations (11), (12), and (14) into this equilibrium condition, normalizing all variables by the capital stock, and utilizing equation (9), equation (16) can be rewritten in terms of the rate of capacity utilization as: ${ }^{9}$

$$
u=c_{w}(1-\beta)\left(\omega_{p} u-i d_{R}\right)+c_{\pi}(1+\beta \eta)\left(\phi \alpha \omega_{p} u+\pi u+i d_{R}\right)+\kappa_{0}+\kappa_{r} \pi u
$$

\footnotetext{
${ }^{9}$ The term $d_{R}$ in equation (17) is workers' net debt (i.e., debt owed to rentiers) to capital stock ratio. This bears a straightforward relationship to the more intuitive debt to income ratio, which is given by $D_{R} / W_{p} N=d_{R} / \omega_{p} u$.
} 
Recalling that, on the basis of equation $(6), \omega_{p}$ can be replaced with $(1-\pi) /(1+\alpha \phi)$, and utilizing equation (9), we can then derive the following expressions for the rates of capacity utilization, profit, and accumulation:

$$
\begin{gathered}
u=\frac{\kappa_{0}+i d_{R}\left[c_{\pi}(1+\beta \eta)-c_{w}(1-\beta)\right]}{\left\{1-\left[c_{\pi}(1+\beta \eta)+\kappa_{r}\right] \pi-\frac{[1-\pi]\left[c_{w}(1-\beta)+c_{\pi}(1+\beta \eta) \phi \alpha\right]}{1+\phi \alpha}\right\}} \\
r=\pi u=\frac{\pi\left[\kappa_{0}+i d_{R}\left(c_{\pi}[1+\beta \eta]-c_{w}[1-\beta]\right)\right]}{\left\{1-\left[c_{\pi}(1+\beta \eta)+\kappa_{r}\right] \pi-\frac{[1-\pi]\left[c_{w}(1-\beta)+c_{\pi}(1+\beta \eta) \phi \alpha\right]}{1+\phi \alpha}\right\}} \\
g_{K}=\kappa_{0}+\frac{\kappa_{r} \pi\left[\kappa_{0}+i d_{R}\left(c_{\pi}[1+\beta \eta]-c_{w}[1-\beta]\right)\right]}{\left\{1-\left[c_{\pi}(1+\beta \eta)+\kappa_{r}\right] \pi-\frac{[1-\pi]\left[c_{w}(1-\beta)+c_{\pi}(1+\beta \eta) \phi \alpha\right]}{1+\phi \alpha}\right\}}
\end{gathered}
$$

The comparative static results for $u, r$ and $g_{K}$ derived from the temporary equilibria in equations (18)-(20) are reported in Table 3. ${ }^{10}$ They reveal several interesting features of the growth process modeled in this paper. Because the responses of $u, r$ and $g_{K}$ with respect to small variations in $\kappa_{0}, \pi, i, d_{R}$, and $\eta$ are always of the same sign, we focus in what follows on comparative static results involving the temporary equilibrium growth rate.

Table 3: Short-Run Comparative Statics

\begin{tabular}{cccccc}
\hline & $\kappa_{0}$ & $\pi$ & $i$ & $d_{R}$ & $\eta$ \\
\hline$u$ & + & $?$ & $?$ & $?$ & + \\
$r$ & + & $?$ & $?$ & $?$ & + \\
$g_{K}$ & + & $?$ & $?$ & $?$ & + \\
\hline \multicolumn{7}{l}{ Positive } & $d_{R}$ is assumed.
\end{tabular}

First, and as expected, $\partial g_{K} / \partial \eta, \partial g_{K} / \partial \kappa_{0}>0$. Since $\eta$ is the propensity to emulate in equation (13) which (given $\beta>0$ ) drives workers' borrowing in equation (12), the first of these derivatives confirms that increased borrowing fuels demand formation and hence growth. This is in keeping with ordinary Keynesian logic. So, too, is the sign of $\partial g_{K} / \partial \kappa_{0}$,

\footnotetext{
${ }^{10}$ The results reported in Table 3 assume $d_{R}>0$ and that the Keynesian stability condition holds (i.e., the common denominator of (18)-(20) is positive.
} 
which suggests that an improvement in the "animal spirits" of firms boosts growth.

The ambiguous signs of the derivatives reported in the third, fourth, and fifth columns of Table 3 demand more extensive discussion. Consider first the results in columns four and five. The servicing of debts sets up a flow of transfer payments from debtors to creditors that (ceteris paribus) is conventionally thought to create a deflationary drag in demand-led growth models. ${ }^{11}$ This is because of the higher marginal propensity to consume of debtor households. But according to Table $3, \partial g_{K} / \partial i, \partial g_{K} / \partial d_{R} \gtrless 0$. The basis of this result is immediately obvious from inspection of the numerator of equation (20), from which it can be seen that:

$$
\frac{d g_{K}}{d i}, \frac{d g_{K}}{d d_{R}} \gtreqless 0 \Longleftrightarrow c_{\pi}(1+\beta \eta)-c_{W}(1-\beta) \gtreqless 0
$$

The intuition for this result is that the redistribution of income from workers to rentiers brought about by increased debt servicing commitments has two effects on consumption spending, which are clearly revealed by writing:

$$
c_{\pi}(1+\beta \eta)-c_{W}(1-\beta)=\left(c_{\pi}-c_{W}\right)+\beta\left(c_{\pi} \eta+c_{W}\right)
$$

The first term on the right hand side of this expression $\left(c_{\pi}-c_{W}<0\right)$ captures the conventional (direct) effect of debt servicing: a redistribution of income from high to low marginal propensity to consume households that depresses total consumption spending ( $c e$ teris paribus $)$. The second term on the right hand side $\left(\beta\left[c_{\pi} \eta+c_{W}\right]>0\right)$ is an unconventional indirect effect of debt servicing on consumption. It captures the fact that as income is redistributed towards rentiers as a result of debt servicing, this both: a) increases rentier income and hence rentier consumption spending and hence (because of emulation effects) $C^{T}$ and hence worker borrowing; and b) decreases worker income and hence workers' consumption from income, thus widening the gap between $C^{T}$ and $C_{W}$ and so increasing worker bor-

\footnotetext{
${ }^{11}$ See, for example, Dutt (2005, 2006) and Hein (2012, chpt.5).
} 
rowing (see equation (12)). In short, income redistribution due to increased debt servicing commitments lowers consumption spending from current income but increases consumption spending financed by workers' borrowing, with the result that its total impact on consumption expenditures (and hence $g_{K}$ ) is ambiguous.

Note also from the expression in (21) that as $\beta \rightarrow 0$ (i.e., borrowing and/or lending norms restrict workers' ability to pursue their consumption target, $C^{T}$ ), the right hand side of (21) tends towards $c_{\pi}-c_{W}<0$. In other words, the more aggressively working households accumulate debt to finance consumption spending, the greater the likelihood that the derivatives in (21) will turn positive. Note also, however, that $\eta>0$ impacts positively on the right hand side of (21). In other words, consumption emulation by working households increases the likelihood that the derivatives in (21) will turn positive. Taken together, these comments demonstrate that it is the combination of borrowing and consumption emulation behavior that determines the possibility that higher debt servicing payments will stimulate the economy.

The ambiguity of the signs of the derivatives in (21) means that one of the central results reported by Setterfield and Kim (2013) - that increased debt servicing commitments provide a source of demand-side stimulus to the economy - remains a possibility even when debtor households adhere to a more conventional pattern of debt servicing behavior (as in this paper). In other words, this result does not altogether depend on the "pecking order" behavior hypothesized by Setterfield and Kim (2013). ${ }^{12}$ This observation poses an obvious question: why has the result in (21) not been observed previously in the literature that considers household debt accumulation as part of the dynamics of a Kaleckian growth process? Inspection of the literature reveals that the answer varies with the contribution at hand. In

\footnotetext{
${ }^{12}$ It should be noted that the result is, however, made more likely by this behavior, since what Setterfield and Kim (2013) show is that increased debt servicing obligations always provide a stimulus to the economy. The intuition for this result is straightforward: with the "pecking order" behavior hypothesized by Setterfield and Kim (2013), workers sacrifice only savings to meet increased debt servicing obligations, while rentiers spend some part of the additional income they receive as a result of the transfer payments created by debt servicing. In this way, a leakage from the circular flow of income (workers' saving) is partially transformed into an injection (rentier spending), boosting aggregate demand formation.
} 
Dutt $(2005,2006)$, for example, there is no emulation effect through which an increase in rentier consumption can stimulate increased borrowing and consumption spending by workers. At the same time, a decline in workers' income (and hence workers' consumption from income) due to increased debt servicing commitments reduces the desired debt level of working households which depresses borrowing and hence consumption spending. ${ }^{13}$ In conjunction with the conventional, direct effect of debt servicing on consumption (as outlined above), this means that the net effect of increased debt servicing commitments on consumption spending (and hence growth) is unambiguously negative.

Kim (2012), meanwhile, features an emulation effect through which increased capitalist consumption will stimulate borrowing and spending by workers, but no accompanying mechanism whereby a fall in workers' income (and hence their consumption from income) also stimulates worker borrowing and spending. From the short run equilibrium solution to this model, it appears to be the case that:

$$
\frac{d u}{d\left(i d_{w}\right)}, \frac{d g_{K}}{d\left(i d_{w}\right)} \gtreqless 0 \Longleftrightarrow(1+\beta) s_{R}-\beta \lesseqgtr 0
$$

where $i d_{w}$ is the total debt servicing commitments (per unit of capital) of workers, $\beta$ is the propensity of workers to emulate capitalist consumption, and $s_{R}$ is capitalists' propensity to save. ${ }^{14}$ However, the Keynesian stability condition in this model requires that $(1+$ $\beta) s_{R}>\kappa_{r}+\beta$, from which it follows that $(1+\beta) s_{R}>\beta$ (since $\kappa_{r}>0$, where $\kappa_{r}$ is the responsiveness of the rate of accumulation to the rate of profit). It must therefore be the case that $d u / d\left(i d_{w}\right), d g_{k} / d\left(i d_{w}\right)<0$ in the expression above - in other words, that an increase in the debt servicing commitments of workers has an unambiguously negative effect on capacity utilization and growth.

Finally, the model developed by Dutt (2008) admits a short run equilibrium solution from which it follows that:

\footnotetext{
${ }^{13}$ See Dutt (2005, p.167) equations (14) and (15) and Dutt (2006, p.347) equations (6) and (7), respectively.

${ }^{14}$ See Kim (2012, p.8), equations (13)-(15).
} 


$$
\frac{d u}{d\left(i k_{w}\right)} \gtreqless 0 \Longleftrightarrow c_{w}-(1+\gamma) c_{c} \gtreqless 0
$$

where $k_{w}<0$ is the debt to capital stock ratio of workers, $\gamma$ is the propensity of working households to emulate capitalists' consumption, and $c_{c}$ is capitalists' propensity to consume. ${ }^{15}$ Noting that $c_{w}-(1+\gamma) c_{c}=\left(c_{w}-c_{c}\right)-\gamma c_{c}$, we can see that a decrease in $i k_{w}<0$ (that is, an increase in workers' debt servicing commitments), will simultaneously: a) reduce aggregate consumption through the conventional direct channel $\left(c_{w}-c_{c}>0\right)$; and b) increase aggregate consumption through the unconventional indirect channel $-\gamma c_{c}<0$, as redistribution of income towards capitalist households increases capitalist consumption which then increases workers' consumption financed by borrowing as a result of emulation effects. This demonstrates that the possibility that increased debt servicing commitments will boost demand-led growth through a combination of emulation and borrowing effects, even when debt servicing behavior is conventional, has been discovered before - even if it has not been explicitly remarked upon. ${ }^{16}$ Taken together, the various elements of the discussion of the result in (21) suggest that not only the precise way in which net-debtor households service their debts, but also the precise way in which these households borrow and seek to emulate the consumption patterns of more affluent households matter for the economy's macrodynamics.

Finally, consider the comparative static results in the third column of Table 3, where the ambiguous sign of $\partial g_{K} / \partial \pi$ suggests that the growth regime can be either wage- or profit-led. First, it follows from the investment function in equation (20) that:

\footnotetext{
${ }^{15}$ See Dutt (2008, p.543), equation (11).

${ }^{16}$ Note that the result described above is not constrained by the Keynesian stability condition, which in Dutt (2008) requires that:

$$
1-(1+\gamma) c_{c} \sigma-c_{w}(1-\sigma)>0
$$

or:

$$
c_{w}-(1+\gamma) c_{c}>\frac{c_{w}-1}{\sigma}
$$

where $\sigma$ is the profit share of income. The term on the right hand side of this last expression is unambiguously negative, so the term on the right hand side can be either positive or (within bounds) negative.
} 


$$
\frac{d g_{K}}{d \pi}=\frac{\partial g_{k}}{\partial \pi}+\frac{\partial g_{k}}{\partial u} \frac{d u}{d \pi}=\kappa_{r} u+\kappa_{r} \pi \frac{d u}{d \pi}
$$

Given that $\kappa_{r} u, \kappa_{r} \pi \gg 0$, the sign of the derivative in equation (22) depends on the sign of $d u / d \pi$. Using equation (18), it can be shown that:

$$
\frac{d u}{d \pi} \gtreqless 0 \Longleftrightarrow\left[\kappa_{0}+i d_{R}\left(c_{\pi}[1+\beta \eta]-c_{W}[1-\beta]\right)\right]\left[\kappa_{r}(1+\alpha \phi)+c_{\pi}(1+\beta \eta)-c_{W}(1-\beta)\right] \gtreqless 0
$$

If we were to assume that there is no managerial class $(\alpha=0)$ and no borrowing and hence no net debt accumulation by working households $\left(\beta, d_{R}=0\right)$, the expression in (23) would become: ${ }^{17}$

$$
\frac{d u}{d \pi} \gtreqless 0 \Longleftrightarrow \kappa_{0}\left[\kappa_{r}+c_{\pi}-c_{W}\right] \gtreqless 0
$$

Comparison of the expressions in (23) and (24) reveals that as in the earlier model of Setterfield and Kim (2013), the introduction of a managerial class coupled with borrowing and debt accumulation by working households seeking to emulate rentiers' consumption patterns has a quantitative but not a qualitative effect on the sign of $\partial g_{K} / \partial \pi$. There is no qualitative effect because in both (23) and (24), the sign of $\partial u / \partial \pi$ and hence $\partial g_{K} / \partial \pi$ is indeterminate: the "paradox of costs" may or may not be observed. There is a quantitative effect, however, because $(1+\alpha \phi),(1+\beta \eta)>1$, and $1-\beta<1$ all affect the size of $d u / d \pi$ (and hence $\left.d g_{K} / d \pi\right)$ in (23) relative to that of $d u / d \pi$ (and hence $d g_{K} / d \pi$ ) in (24). In the first instance, $\kappa_{r}(1+\alpha \phi)+c_{\pi}(1+\beta \eta)-c_{W}(1-\beta)>\kappa_{r}+c_{\pi}-c_{W}$. Ceteris paribus, this makes the expression in (23) larger than that in (24), which increases the likelihood that growth will be profit-led. A similar result is obtained in Setterfield and Kim (2013). ${ }^{18}$ But

\footnotetext{
${ }^{17}$ In this case, the model conforms to a canonical two-class neo-Kaleckian growth model in which workers save some part of their wage income.

${ }^{18}$ In Setterfield and $\operatorname{Kim}(2013), d u / d \pi>0$ and hence $d g_{K} / d \pi>0$ (profit-led growth) is unambiguously more likely than in the two-class model with no net borrowing by workers from the capitalist class.
} 
in contrast to this earlier contribution, the sign of the derivative in (23) depends also on $c_{\pi}(1+\beta \eta)-c_{W}(1-\beta) \gtrless 0$ in the first bracketed term of the expression. As a result of this term, the size of the derivative in (23) relative to that in (24) is ambiguous. What this means is that in the model developed in this paper, the effect of introducing a managerial class coupled with borrowing and debt accumulation by working households on the prospects for wage- rather than profit-led growth is ambiguous. This result provides further evidence that the precise nature of debt servicing behavior matters for the economy's macrodynamics.

\section{Debt Dynamics and the Sustainability of Steady State Growth}

The question addressed in this section is whether or not steady-state growth is financially sustainable, given the assumptions made about workers' debt servicing behavior. Note that from the definition of $d_{R}$, it follows that:

$$
\begin{aligned}
\dot{d}_{R} & =\frac{\beta\left(C^{T}-C_{W}\right)-\dot{D_{W}}}{K}-g_{K} d_{R} \\
& =\frac{\beta\left(\eta C_{R}-C_{W}\right)-\dot{D_{W}}}{K}-g_{K} d_{R} \\
& =\beta \eta c_{\pi}\left(\omega_{r} u+\pi u+i d_{R}\right)-\left(1-[1-\beta] c_{W}\right)\left(\omega_{p} u-i d_{R}\right)-g_{K} d_{R}
\end{aligned}
$$

Solving for and identifying the stability properties of the steady state values of $d_{R}$ requires that we substitute equations (18) and (20) into equation (25) and set $\dot{d}_{R}=0$. But without undertaking these operations, inspection of equation (25) reveals at a glance two things about the stability properties of the economy's debt dynamics. First, because $g_{K}$ is a function of $d_{R}$ (see equation (20)), equation (25) will take the usual quadratic form. Second, as revealed

in Table $3, \partial g_{K} / \partial d_{R} \gtrless 0$. This implies that, in equation (25), the $g_{K} d_{R}$ term can be either increasing or decreasing in $d_{R}$. On one hand, if $\partial g_{K} / \partial d_{R}<0$, a higher value of $d_{R}$ may 
generate a destabilizing force, increasing the likelihood that $\partial \dot{d}_{R} / \partial d_{R}>0$ at higher values of $d_{R}$. The resulting u-shape of the $\dot{d}_{R}$ function implied by this observation (and depicted in Figure 1) conforms to the conventional u-shaped relationship found in the literature (see, for example, Hein (2012, pp.94-98)). In this case, the smaller of the two roots of equation (25), denoted by $d_{R 2}$ in Figure 1, will correspond to the stable steady state solution of equation (25). On the other hand, if $\partial g_{K} / \partial d_{R}>0$, a higher value of $d_{R}$ may generate a stronger stabilizing force, increasing the likelihood that $\partial \dot{d}_{R} / \partial d_{R}<0$ at higher values of $d_{R}$. The inverse u-shape of the $\dot{d}_{R}$ function implied by this observation (and depicted in Figure 2) differs from the conventional u-shaped relationship in Figure 1, and implies that the larger of the two roots of equation (25), denoted by $d_{R 1}$ in Figure 2, will now correspond to the stable steady state solution of equation (25).

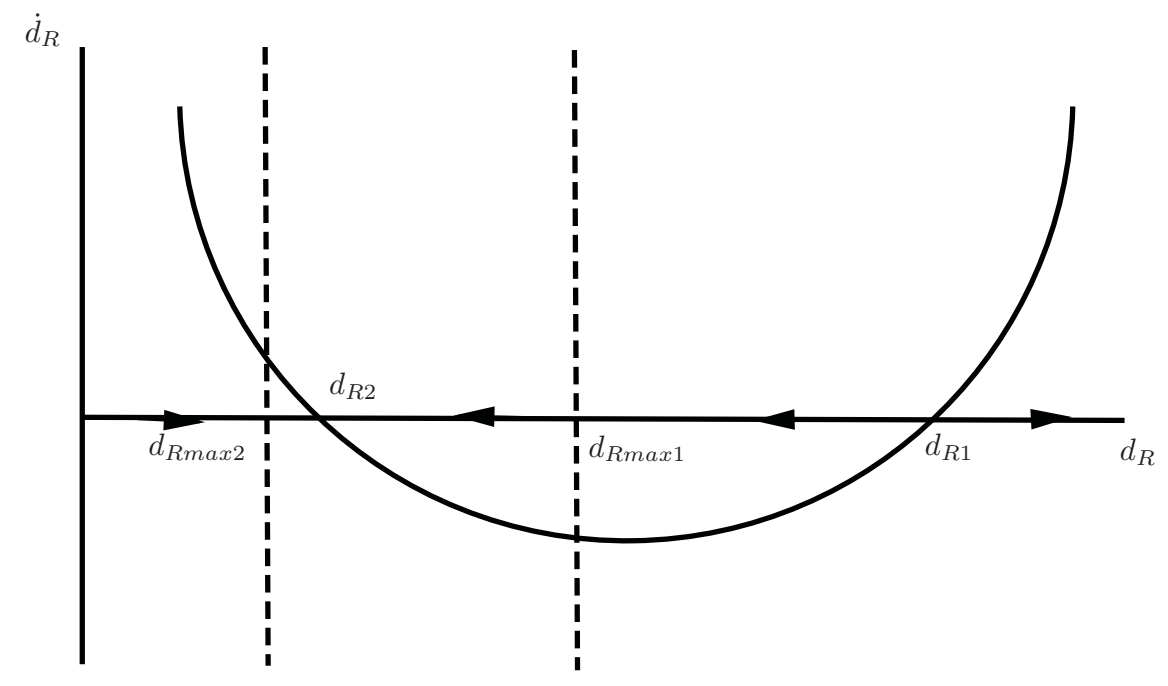

Figure 1: Debt dynamics: the "conventional" case

We can also consider the proximity of the stable steady state value of $d_{R}$ to the maximum feasible net debt to capital ratio of working households, $d_{R \max }$. This allows us to reflect on the sustainability of the growth process. First note that from our previous description of workers' consumption and debt servicing behavior in equation (14), we can define a feasibility coefficient: 


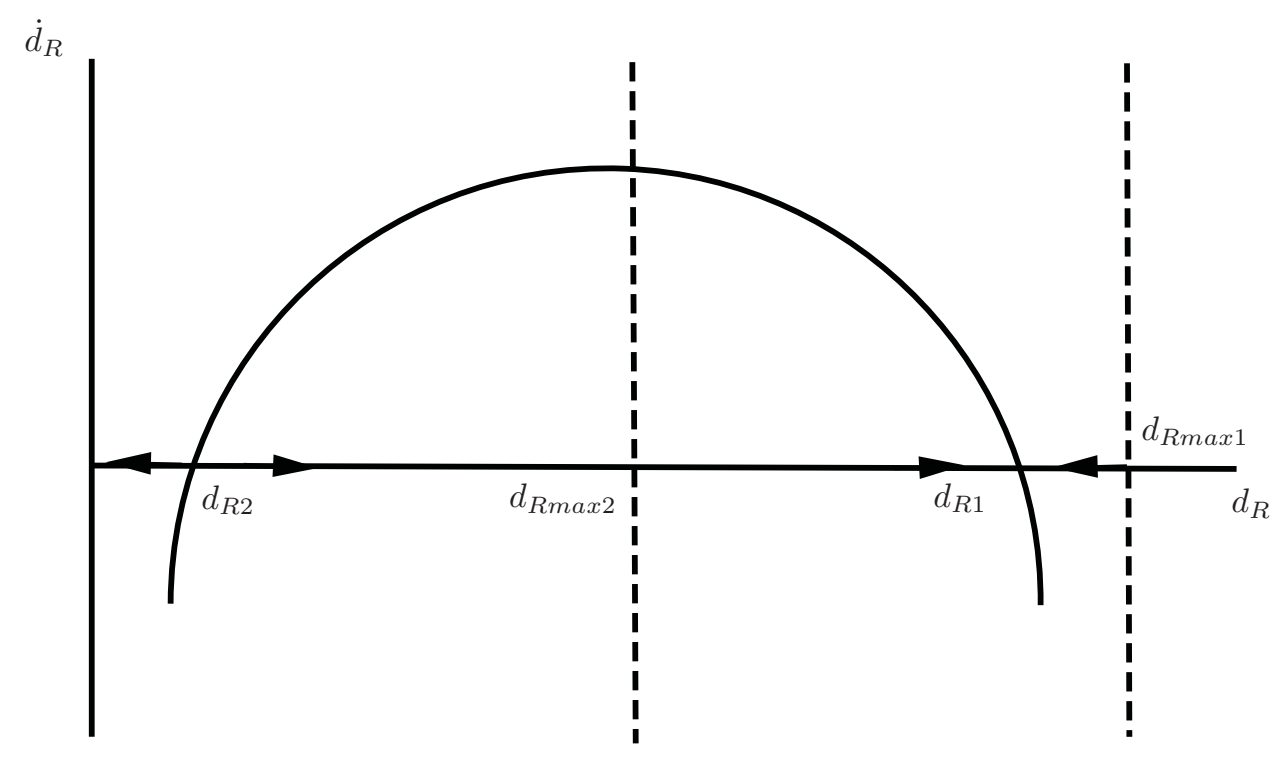

Figure 2: Debt dynamics: the "unconventional" case

$$
c=\omega_{p} u-i d_{R}
$$

that must satisfy $c \geq 0$ in order for working households to continue servicing their debts. By setting $c=0$ we can identify the maximum net debt to capital ratio that workers can sustain as:

$$
\begin{aligned}
d_{\text {Rmax }} & =\omega_{p} u / i \\
& =\frac{\kappa_{0}(\pi-1)}{i\left[c_{\pi}(1+\beta \eta)+\kappa_{r} \pi-1\right](1+\phi \alpha)}
\end{aligned}
$$

If our debt dynamics are conventional as in Figure 1 (where $d_{R 2}$ is the stable, steady-state debt to capital ratio), then with $d_{R \max }=d_{R \max 1}, d_{R} \leq d_{R \max 1}$ initially suffices to ensure that convergence to $d_{R 2}$ is feasible. The accompanying steady-state growth rate will then be sustainable indefinitely (ceteris paribus). Only if $d_{R \max }$ is very low-as exemplified by $d_{R \max 2}$, for instance-will the growth process be unsustainable. In this case, even if $d_{R} \leq d_{R \max 2}$ initially, convergence towards $d_{R 2}$ will eventually violate the feasibility condition $c \geq 0$ and 
the growth regime will experience a crisis. ${ }^{19}$

Now consider Figure 2, where $d_{R 1}$ is the stable equilibrium. If $d_{R \max }=d_{R \max 1}$, then $d_{R} \leq d_{R \max 1}$ initially will ensure convergence to the stable, steady-state debt to capital ratio $d_{R 1}$. Once again, the accompanying steady-state growth rate will be sustainable indefinitely (ceteris paribus). If, however, $d_{R \max }=d_{R \max 2}$, then even if $d_{R} \leq d_{R \max 2}$ initially, the stability of $d_{R 1}$ will eventually pull the debt to capital ratio above its maximum sustainable value. ${ }^{20}$ The borrowing behavior of workers is unsustainable and the economy will eventually experience a crisis.

\subsection{Numerical Analysis}

We now examine the effects of workers' debt servicing behavior on the sustainability of the growth process by means of a numerical analysis based on empirically plausible parameter values designed to represent conditions prevalent during the Neoliberal growth regime (19802007 ) in the US. These parameter values are reported in Table 4, and are identical to the values used by Setterfield and Kim (2013) with the exception of $\kappa_{0}$. Following Setterfield and Kim (2013), $\kappa_{0}$ is set so that, in conjunction with the other parameters in Table 4, equation (18) produces a capacity utilization rate of approximately 80 percent when evaluated at the steady-state value of $d_{R}$. Again following Setterfield and Kim (2013), the propensity of working households to emulate rentier consumption, $\eta$, is calculated as:

$$
\eta=\lambda \delta
$$

where $\lambda$ is the emulation parameter calculated by Ravina (2007) and $\delta$ is a "scaling parameter" that captures the ratio of consumption by the upper-middle class (capitalists and the working rich) to consumption by the median rentier family, proxied by the ratio of CEO pay to median rentier household income.

\footnotetext{
${ }^{19}$ In this context a "crisis" refers only to a breakdown in the dynamics of the model as specified. Exactly how the economy reacts to these circumstances is beyond the scope of the current paper.

${ }^{20}$ The exception is if $d_{R}<d_{R 2}$ initially. In this case, workers will eventually cease to be net debtors.
} 
Table 4: Parameter values

\begin{tabular}{|c|c|c|}
\hline Parameter & Value & Source \\
\hline$c_{W}$ & 0.94 & $\begin{array}{c}\text { Authors' calculations based on } \\
\text { Bunting (1998) }\end{array}$ \\
\hline$c_{\pi}$ & 0.20 & Setterfield and Budd (2011) \\
\hline$\beta$ & 0.10 & Authors' calculations ${ }^{1}$ \\
\hline$\lambda$ & 0.29 & Ravina (2007) \\
\hline$\delta$ & 74.89 & $\begin{array}{l}\text { Authors' calculations based on } \\
\text { Mishel and Sabadish (2012) and } \phi\end{array}$ \\
\hline$\phi$ & 2.27 & $\begin{array}{c}\text { Authors' calculations based on } \\
\text { Mishel et al. (2007) }\end{array}$ \\
\hline$\alpha$ & 0.25 & Authors' calculations ${ }^{2}$ \\
\hline$\omega_{p}$ & 0.42 & $\begin{array}{l}\text { Authors' calculations based on } \\
\text { Mohun (2006), Figure } 7\end{array}$ \\
\hline$\pi$ & 0.34 & Authors' calculations ${ }^{3}$ \\
\hline$\kappa_{0}$ & 0.095 & Authors' calculations ${ }^{4}$ \\
\hline$\kappa_{r}$ & 0.5 & $\begin{array}{l}\text { Lavoie and Godley (2001-02), } \\
\text { Skott and Ryoo (2008) }\end{array}$ \\
\hline$i$ & 0.0481 & $\begin{array}{c}\text { Authors' calculations based on } \\
\text { World Bank Data }\end{array}$ \\
\hline
\end{tabular}

1. Set in accordance with other parameters to satisfy the Keynesian stability condition.

2. Based on production workers accounting for 80 per cent of total employment. See (Mishel et al., 2007, p.118).

3. Set in accordance with $\pi=1-(1+\alpha \phi) \omega_{p}$.

4. Set in accordance with other parameters to yield capacity utilization rate of approximately 80 per cent.

5. See data.worldbank.org. 
Using the parameter values in Table 4, the debt dynamics of the Neoliberal growth regime are revealed as "conventional" (i.e., similar to those discussed in Figure 1 above). This is made clear in Figure 3. Under the assumptions they make about workers' debt servicing behavior, Setterfield and Kim (2013) show that the debt dynamics of the Neoliberal regime are unequivocally unconventional (as in Figure 2). The result in Figure 3 therefore demonstrates that, under plausible conditions (as represented by the parameter values in Table 4), the way in which debtor households service their debts has an important qualitative effect on the economy's debt dynamics. Specifically, when debts are serviced conventionally (i.e., when debt servicing is treated as an initial deduction from income), the debt dynamics of the Neoliberal growth regime are transformed from unconventional (Figure 2) to conventional (Figure 1).

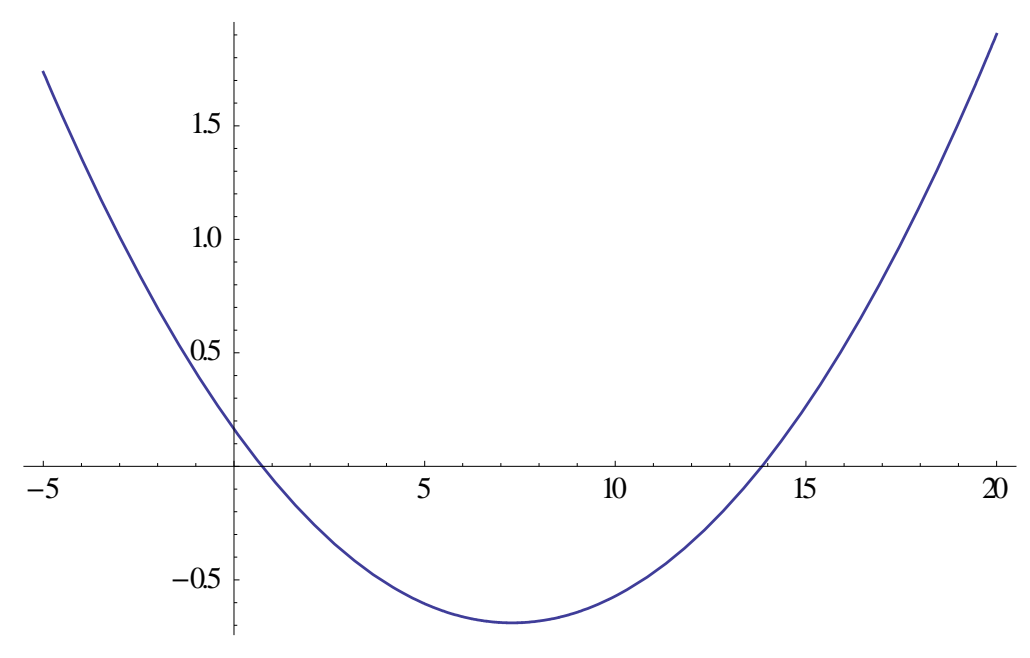

Figure 3: Simulated debt dynamics of the Neoliberal growth regime

The sustainability of the growth process is explored in Table 5, which reports the values of the larger (unstable) and smaller (stable) roots of equation (25), $d_{R 1}$ and $d_{R 2}$, the maximum debt to capital ratio that can be sustained by working households $\left(d_{R m a x}\right)$, and the feasibility 
Table 5: Sustainability of Growth in Two Growth Regimes

\begin{tabular}{lcccc}
\hline & $d_{R 1}$ & $d_{R 2}$ & $d_{R} \max$ & $c$ \\
\hline Neoliberal & 13.845 & 0.740 & 4.251 & 0.305 \\
Golden Age & 9.685 & -0.104 & 1.589 & 0.154 \\
\hline
\end{tabular}

coefficient, $c$, evaluated at the stable steady state $d_{R 2}$ :

$$
c=\omega_{p} u-i d_{R 2}
$$

Table 5 reveals that the Neoliberal growth regime is sustainable for a large range of initial values of $d_{R}$ (given by $\left.d_{R} \leq 4.251\right)$. The stable steady-state value of $d_{R}\left(d_{R 2}=0.740\right)$ is positive but well below $d_{R \max }=4.251$. The feasibility coefficient $c=0.305$ indicates that at $d_{R 2}$, the steady-state debt to capital ratio of working households lies well within the feasible set of workers' debt servicing capabilities. Table 5 also shows that the Golden Age growth regime - which in this exercise differs numerically from the Neoliberal regime only in terms of the key distributional parameters $\omega_{p}, \omega_{r}, \pi$, and $\eta$ - has qualitatively similar characteristics of sustainability, with $d_{R 2}=-0.104<1.589=d_{R \max }$ and $c=0.154 .{ }^{21}$ The obvious contrast here is with the results reported in Setterfield and Kim (2013), where the Neoliberal regime is shown to be unsustainable because of its distributional characteristics. Table 5 demonstrates that with conventional debt servicing behavior, this result no longer holds. In other words, even with the distributional changes associated with the transition from the Golden Age to the Neoliberal regime, the growth process remains sustainable as long as debtor households treat debt servicing obligations as a deduction from income.

The results of this analysis suggest that in addition to changing qualitative characteristics of the economy's debt dynamics (as illustrated in Figure 3), the treatment of debt servicing as a deduction from income (as opposed to a household expense that is accommodated by

\footnotetext{
${ }^{21}$ The exact values of the Golden Age distributional parameters used in the calculations reported in the second row of Table 5 are $\omega_{p}=0.48, \omega_{r}=0.2304, \pi=0.2896$, and $\eta=2.92$. These values are derived from the sources used to evaluate $\omega_{p}, \omega_{r}, \pi$, and $\eta$ during the Neoliberal era, as previously reported in Table 4 .
} 
sacrificing savings) has a decisive effect on the sustainability of the Neoliberal growth regime.

Specifically, the susceptibility of the latter to its distributional regime (as demonstrated by Setterfield and Kim (2013)) would appear to depend on the precise debt servicing behavior of working households.

\section{Conclusion}

Following Dutt (2005, 2006, 2008), Hein (2012), and Kim (2012), this paper extends a conventional Kaleckian growth model to incorporate consumption emulation and borrowing behavior by working households. Particular attention is paid to the precise manner in which debtor households service their debts and its impact on macroeconomic performance, the purpose being to investigate whether or not the results of Setterfield and Kim (2013) survive if households service their debts "conventionally" - that is, by treating debt servicing commitments as an initial deduction from income and then consuming some fraction of what remains. To this end, short-run equilibrium outcomes and the comparative statics associated with them are derived. The effects of debt servicing behavior on the sustainability of the growth process is then explored by means of a numerical analysis, in which attention is focused on the impact of changes in the distributional regime.

Using the results reported in Setterfield and Kim (2013) as a foil, the results in this paper suggest that debt servicing behavior can have important quantitative and qualitative effects on the economy's macrodynamics, affecting its comparative statics (the response of growth to debt servicing commitments and the profit share), its debt dynamics (as captured by the "conventional" versus "unconventional" functional form of the expression for the rate of change of the debt to capital ratio), and sustainability of the growth regime in response to the imposition of a particular (Neoliberal) distributional configuration. These findings confirm the hypothesis that the precise manner in which debtor households service their debts is important for macroeconomic performance. This, in turn, suggests that as a microcosm 
of "financialized" capitalism, household debt servicing behavior warrants more extensive empirical study. 


\section{References}

Asimakopulos, Athanasios (1975, August). "A Kaleckian theory of income distribution." Canadian Journal of Economics 8(3), 313-333.

Atkinson, Anthony B., Thomas Piketty, and Emmanuel Saez (2011). "Top incomes in the long run of history." Journal of Economic Literature 49, 3-71.

Barba, Aldo and Massimo Pivetti (2009). "Rising household debt: Its causes and macroeconomic implications - a long-period analysis." Cambridge Journal of Economics 33(1), $113-137$.

Bartolini, Stefano, Luigi Bonatti, and Francesco Sarracino (2014). "The great recession and the bulimia of us consumers: deep causes and possible ways out." Cambridge Journal of Economics 38, 1015-1042.

Blecker, Robert (2002). "Distribution, demand, and growth in neo-Kaleckian macro models." In Mark Setterfield, ed., The Economics of Demand-Led Growth: Challenging the Supply-Side Vision of the Long Run, pp. 129-152. Cheltenham: Edward Elgar.

Bunting, David (1998). "Distributional basis of aggregate consumption." Journal of Post Keynesian Economics 20(3), 389-413.

Cynamon, Barry Z. and Steven M. Fazzari (2008). "Household debt in the consumer age: Source of growth-risk of collapse." Capitalism and Society 3(2), Article 3.

Cynamon, Barry Z. and Steven M. Fazzari (2014). "Household income, demand, and saving: Deriving macro data with micro data concepts." SSRN: http://dx.doi.org/10.2139/ssrn.2211896.

Dutt, Amitava K. (2005). "Consumption, debt and growth." In Mark Setterfield, ed., Interactions in Analytical Political Economy, pp. 155-78. Armonk, NY: M.E. Sharpe. 
Dutt, Amitava K. (2006). "Maturity, stagnation and debt: a Steindlian approach." Metroeconomica 57, 339-364.

Dutt, Amitava K. (2008). "The dependence effect, consumption and happiness: Galbraith revisited." Review of Political Economy 20(4), 527-550.

Frank, Robert H., Adam Seth Levine, and Oege Dijk (2014). "Expenditure cascades." Review of Behavioral Economics 1(12), 55-73.

Harris, Donald J. (1974). "The price policy of firms: The level of employment and distribution of income in the short run." Australian Economic Papers 13, 144-151.

Hein, Eckhard (2012). The Macroeconomics of Finance-dominated Capitalism - and its Crisis. Cheltenham, UK: Edward Elgar.

Kahneman, Daniel, J.L. Knetsch, and Richard Thaler (1986). "Fairness as a constraint on profit seeking: entitlements in the market." American Economic Review 76, 728-41.

Kim, Yun K (2012). "Emulation and consumer debt: Implications of keeping-up with the jones." Working Paper 1208, Trinity College Working Paper Series.

Lavoie, Marc and Wynne Godley (2001-02). "Kaleckian models of growth in a coherent stock-flow monetary framework." Journal of Post Keynesian Economics 24(2), 277311.

Mishel, Lawrence, Jared Bernstein, and Sylvia Allegretto (2007). The State of Working America 2006/2007. Ithaca, NY: Cornell University Press.

Mishel, Lawrence and Natalie Sabadish (2012, May). "CEO pay and the top 1 percent: how executive compensation and financial-sector pay have fueled income inequality." Issue brief 331, Economic Policy Institute.

Mohun, Simon (2006). "Distributive shares in the US economy, 1964-2001." Cambridge Journal of Economics 30(3), 347-370. 
Onaran, Özlem, Engelbert Stockhammer, and Lukas Grafl (2011). "Financialisation, income distribution and aggregate demand in the USA." Cambridge Journal of Economics 35, $637-661$.

Palley, Thomas I. (2002). "Economic contradictions coming home to roost? does the us economy face a long-term aggregate demand generation problem?" Journal of Post Keynesian Economics 25, 9-32.

Palley, Thomas I. (2012). "Wealth and wealth distribution in the neo-kaleckian growth model." Journal of Post Keynesian Economics 34, 449-70.

Palley, Thomas I. (2013a). "A Kaldor-Hicks-Goodwin-Tobin-Kalecki model of growth and distribution." Metroeconomica 64(2), 319345.

Palley, Thomas I. (2013b). "The middle class in macroeconomics and growth theory: a three class neo- $k$ aleckian-goodwin model." Paper presented at the Meetings of the Eastern Economic Association, New York, May 2013.

Pasinetti, Luigi L. (1962). "Rate of profit and income distribution in relation to the rate of economic growth." Review of Economic Studies 29, 267-79.

Piketty, Thomas and Emmanuel Saez (2003, February). "Income inequality in the United States, 1913-1998." Quarterly Journal of Economics 118(1), 1-39.

Ravina, Enrichetta (2007). "Habit formation and keeping up with the Joneses: evidence from micro data." http://ssrn.com/abstract $=928248$.

Setterfield, Mark (2013). "Wages, demand and us macroeconomic travails: Diagnosis and prognosis." In Steve M. Fazzari Cynamon, Barry Z. and Mark Setterfield, eds., After the Great Recession: The Struggle for Economic Recovery and Growth, pp. 158-184. Cambridge University Press. 
Setterfield, Mark and Andrew Budd (2011). "A Keynes-Kalecki model of cyclical growth with agent-based features." In Philip Arestis, ed., Microeconomics, Macroeconomics and Economic Policy: Essays in Honour of Malcolm Sawyer, pp. 228-50. London: Palgrave Macmillan.

Setterfield, Mark and Yun K. Kim (2013). "Debt servicing, aggregate consumption, and growth." Trinity College Department Of Economics Working Paper 13-16.

Skott, Peter (1989). Conflict and effective demand in economic growth. Cambridge: Cambridge University Press.

Skott, Peter (2014). "Inceasing inequality and financial fragility." Review of Radical Political Economics 45, 478-488.

Skott, Peter and Soon Ryoo (2008). "Macroeconomic implications of financialization." Cambridge Journal of Economics 32(?), 827-862.

Stockhammer, Engelbert (1999). "Robinsonian and kaleckian growth. an update on postkeynesian growth theories." Working Paper 67, Vienna University of Economics and Business Administration. http://ideas.repec.org/p/wiw/wiwwuw/wuwp067.html.

Wisman, Jon D. (2013). "Wage stagnation, rising inequality and the financial crisis of 2008." Cambridge Journal of Economics 37, 921-945.

Wolff, E. N. (2010). "Recent trends in household wealth in the United States: rising debt and the middle-class squeeze - an update to 2007." Levy Economics Institute Working Paper No. 589.

Wolff, Edward N. and Ajit Zacharias (2009). "Household wealth and the measurement of economic well-being in the united states." Journal of Economic Inequality 7, 83-115.

Wolff, Edward N. and Ajit Zacharias (2013). "Class structure and economic inequality." Cambridge Journal of Economics 37, 1381-1406. 